\title{
Cogito ergo sum
}

\author{
G. Angelos ${ }^{1}$
}

Received: 29 March 2020 / Accepted: 11 April 2020 / Published online: 18 April 2020

(c) Springer Nature Switzerland AG 2020

\section{Dear Sir,}

What is real? So much of what we are experiencing in the current COVID-19 pandemic seems beyond imagination. Times such as these bring to mind early scientists, who, through systematic doubt, created a foundation from which truth could be ascertained. Rene Descartes, asserted, "je pense, donc je suis" (I think therefore I am). Essentially, doubting our existence served as a basis to establish a reality of mind. How profound, yet remarkably simple. Yet so much routine, like the well-played grooves of an old vinyl record, invariably leads to habitualization, harmonious comfort that in our current world is terribly dangerous.

Existence was challenged, along with all that I knew, when I operated on my first COVID-19 patient this past week. It was a rule out, but that did not matter, as I was forced to start from yet another reminder of my BA in philosophy, the tabula rasa, i.e. Locke's theory that humans are at birth a clean slate. We had to rethink the entirety of the conventional operative approach given how little has been established regarding risk, in the setting of COVID-19 and its transmission [1]. Our consent had to be verbal, as paper was a potential vector, if you will, of unknown infection. The patient had to be both draped and masked for transport, dressed as if traveling to a morgue, thus requiring continuous reinforcement of life.

The negative pressure OR, as the patient's room on the floor, was necessarily "closed", such that we had to deliberately limit entry and exit as a single group.... and as we all diligently thought over each and every step, with each and every moment, we truly "were" and that was so very real.

As I look back on so many other aspects of the case that was for me entirely novel, which included yelling (not my routine) in the OR to be heard over the constant hum of

G. Angelos

gangelosmd@gmail.com

1 Department of Surgery, Avera Marshall Regional Medical

Center, 300 S. Bruce Street, Marshall, MN 56258, USA our powered air purifying respirators [2] we all squinted through scratched plastic eye shields, but saw as clearly as anyone how drastically surgery was changing together with the world in which we were operating. We chose to perform the case laparoscopically, thus minimizing peri- and post-operative narcotics and exposures, in a patient already a respiratory cripple due to comorbidity, for whom a stoma was ultimately necessary given that newly diagnosed carcinomatosis was causing acute obstruction. However, despite diligent suctioning and filtration, this itself was a risk as it has been suggested that aerosols and plumes secondary to laparoscopy are a potential, if not greater, source of transmission [3].

Innumerable thickets of the mightiest trees have certainly fallen in so many forests, although we have not all been there to hear the sounds. Our ever-shrinking world has now stopped and grown larger by six feet, a distance which I doubt we will be able to negotiate beyond for some time. And I am myself struggling for meaning in much the way centers are struggling for resources, absent masks and gloves, to protect our brothers in arms caring for those on the "front lines".

Let us think and be... and face this new challenge with the thoughtful zeal of early philosophical thinkers and build upon a scientific past so that we can assure our future.

Acknowledgements I would like to thank Dr. Roberto Bergamaschi, who inspired me to write this letter, but more importantly has inspired my professional journey and for that these few words would never be enough.

Funding None.

\section{Compliance with ethical standards}

Conflict of interest The author declares that he has no conflict of interest. 


\section{References}

1. Lewis D (2020) Is the Coronavirus airborne? Experts can't agree. Nature. https://doi.org/10.1038/d41586-020-00974-w (Epublished on April 02, 2020. Accessed on April 05, 2020)

2. Roberts V (2014) To PAPR or not to PAPR? Can J Respir Ther 50(3):87-90 (PMID: 26078617)

3. Li CI, Pai JY, Chen CH (2020) Characterization of smoke generated during the use of surgical knife in laparotomy surgeries. J Air
Waste Manag Assoc. 70(3):324-332 (Epub 2020 Feb 12. PMID: 31961784)

Publisher's Note Springer Nature remains neutral with regard to jurisdictional claims in published maps and institutional affiliations. 